\title{
Multifunctional method for remote monitoring of the environment in the area of nuclear facilities
}

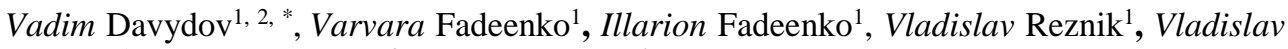 \\ Kruglov $^{1}$, Nikita Popovskiy ${ }^{3}$, and Vasiliy Rud $^{2}$ \\ ${ }^{1}$ Higher School of applied physics and space technologies, Peter the Great Saint Petersburg \\ Polytechnic University, Saint Petersburg, 195251, Russia \\ ${ }^{2}$ All Russian Research Institute of Phytopathology, Moscow Region 143050, Russia \\ ${ }^{3}$ The Bonch-Bruevich Saint Petersburg State University of Telecommunications, Saint Petersburg \\ 193232, Russia
}

\begin{abstract}
In a paper the method for remote monitoring of the radiation characteristics of the environment in the area of the nuclear power plant is considered. To solve this problem, the need to use remote methods of environmental monitoring is justified A method is proposed for determining radioactive formations in the atmosphere using a radar station. Using the methodology for determining radioactive formations in the atmosphere by changing the reflection coefficient of an electromagnetic wave from a given formation is justified. Calculation of changes in the reflection coefficient of an electromagnetic wave from a radioactive formation in the atmosphere for different climatic conditions is calculated. The results of studies of radioactive contamination in the atmosphere are presented. The advantages of the method developed by us in comparison with others are noted. The directions of scientific research to expand the functionality of the method developed by us are determined.
\end{abstract}

\section{Introduction}

The world experience shows that more and more electric energy is required for the sustainable development of society in various directions every year. Especially it is required in industry, services and personal life [1-7]. It happens against the background of a decrease in stocks of various types of fuel and environmental degradation [7-13]. One of the solutions to this complex problem (increasing the volume of generated electric energy with minimal environmental impact) is the development of nuclear energy [14-21].
The nuclear power plant (NPP) is a source of increased radiation hazard during operation. Special attention is paid to monitoring the radiation situation on the territory of the NPP, so in the area of its location, including the atmosphere [6, 9, 22-27]. Various methods are used to detect radioactive substances and emissions into the atmosphere. Remote methods are considered the most promising and safe. It is especially advisable to use them to determine the pollution of the surface layer of the atmosphere by potentially dangerous objects, including radioactive ones. The

*Corresponding author: davydov_vadim66@mail.ru 
radar method has several advantages over gamma-ray telescopy, thermal imaging, spectroscopy using laser radiation of various ranges, etc. [26-33]. The radar method surpasses these methods in detection range, sensitivity, data processing time and spatial resolution [24-43].

The most radar methods are based on measuring the secondary effects of radioactivity, that is reduces the effectiveness of monitoring the state of the environment, especially at long ranges, under bad weather conditions significantly. Therefore, the development of new and improvement of the used radar methods operating in a wide range of weather conditions is an extremely urgent task. One such solution may be proposed by us the radar method for remote monitoring of the environment with direct measurement of the degree of ionization of the air volume irradiated by a radioactive release.

\section{Methods}

The previous experiments of earlier [26, 34-40, 44-46] are showed that in the event of atmospheric contamination with a radioactive impurity in it due to ionization of the air, ionization formations appear - plasmoids. The transverse dimensions of these formations depend on the area of contamination (general case). The shape of the plasmoid is transformed in the presence of wind. Numerous experiments have made it possible to establish that the sizes of plasmoids can vary from several tens of meters to thousands of meters in the transverse direction to radioactive release and up to several hundred meters in height. A feature of these formations is their resistance to various external influences (humidity, wind, etc.).

The Ionization formations (plasmoid) need to be considered ion-ion rather than electron-ion formations. It can be explained that the oxygen in the atmosphere is $10^{13}$ times greater than the positive ions at a radiation dose rate of 1 $\mathrm{R} / \mathrm{h}$. Capture of ions of water molecules by radioactive ions will lead to ion-drop formations. These formations will have different concentrations depending on the height $H$. Figure 1 shows the concentration of positively charged water droplets depending on the height $\mathrm{H}$.

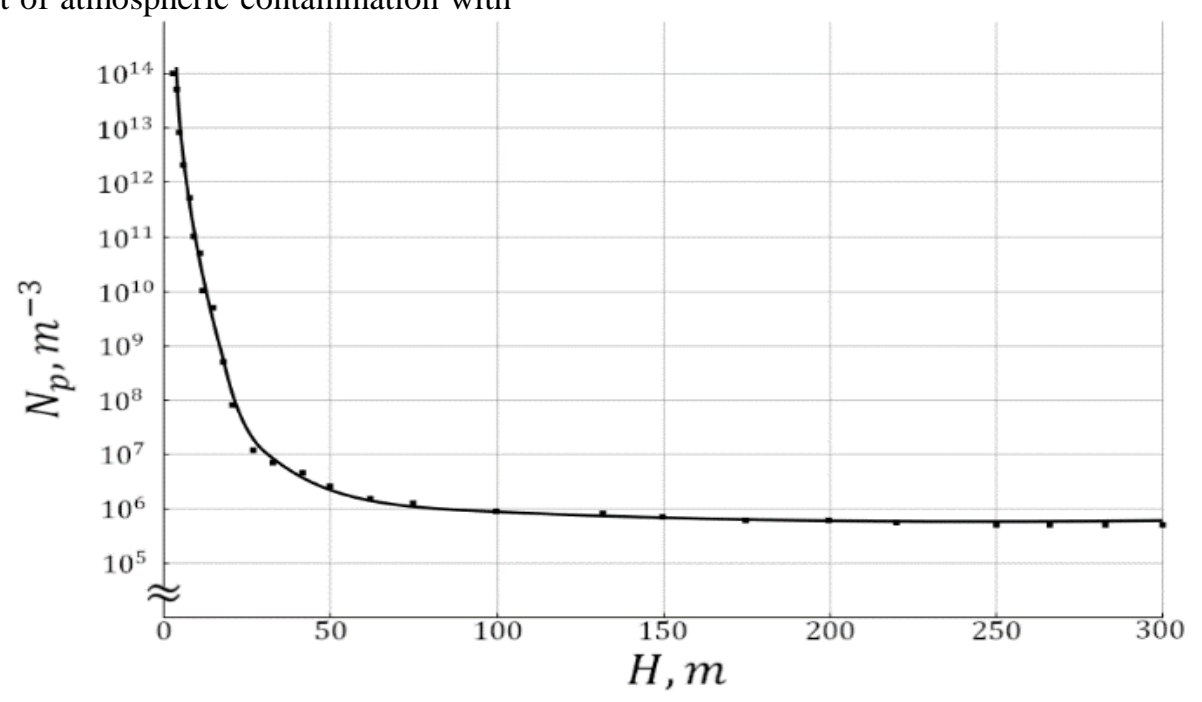

Fig. 1. Dependence of change of concentration $\mathrm{N}_{\mathrm{p}}$ of positively charged water drops on the height $\mathrm{H}$ above the Earth 's surface. 
Analysis of the distribution of carriers shows that there is a rather shallow decline with an increase in height. This means that the plasmon formed by the radioactive contamination will have a layered structure. It will provide good stability of the plasmon under various weather conditions.

It will change the permittivity value $\varepsilon$ of the atmosphere in the region of radioactive contamination. The value of $\varepsilon$ can be estimated by the following formula:

$$
\varepsilon=1-\frac{4 \pi N_{e} e^{2}}{m_{f}\left(\omega^{2}+v^{2}\right)}-\frac{4 \pi N_{+} e^{2}}{M_{+}\left(\omega^{2}+v^{2}\right)}-\frac{4 \pi N_{-} e^{2}}{M_{-}\left(\omega^{2}+v^{2}\right)}
$$

where $\mathrm{v}-$ the impact frequency, $\omega-$ the electromagnetic wave frequency, $\mathrm{M}_{+}=\mathrm{M}_{-}=\mathrm{M}_{\mathrm{i}}-$ the ion mass, $\mathrm{m}_{\mathrm{e}}-$ the electron mass, $\mathrm{N}_{\mathrm{e}}-$ electron concentration,

$\mathrm{N}_{+}-$positive ion concentration, $\mathrm{N}_{-}-$ negative ion concentration.

The change in the value of the air space in which the plasmons are formed will change the effective electric field (the intensity of the electric field changes) and conductivity compared to a part of the air without radioactive contamination.

Figure 2 shows the dependence the intensity of the natural electric field of the atmosphere on the level of radioactive contamination.

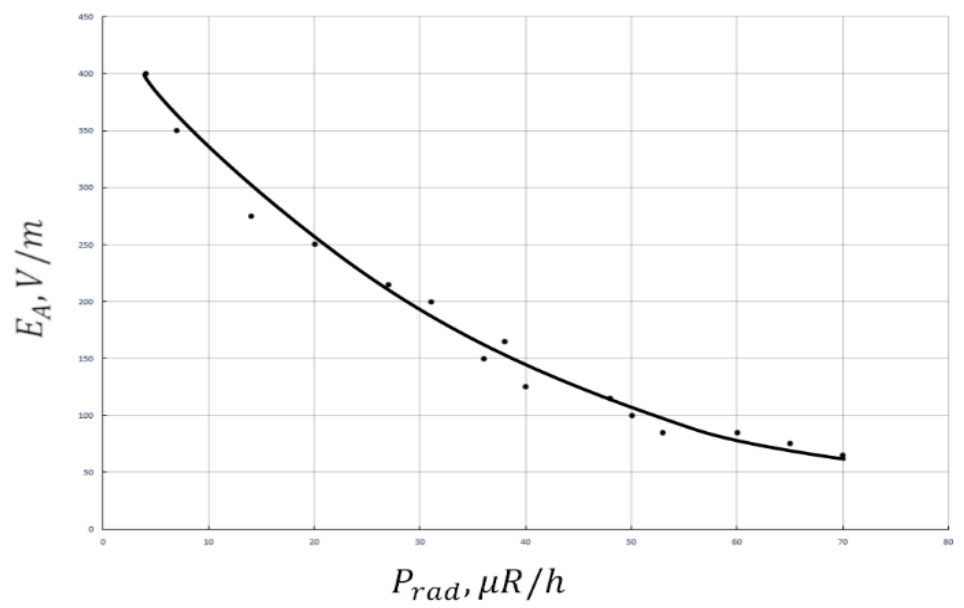

Fig. 2. Dependence of the change in the intensity $E_{A}$ of the electric field of the atmosphere at the height of $100 \mathrm{~m}$ on the power $\mathrm{P}_{\mathrm{rad}}$ of the exposure dose of irradiation.

The results show that it is necessary to solve the problem of estimating the reflection coefficient $\mathrm{R}$ of the electromagnetic wave from the plasmoid as a function of the wavelength of the radar radiation in order to measure the level of radioactive contamination of the atmosphere. This issue did not explore in detail earlier. The heterogeneity of the spatial distribution of positively charged ions was not discussed in detail. Our research solves the problem associated with the determination of the dependence $R(\lambda)$. Figure 3 shows a structural diagram of the implementation of our remote method of detecting radioactive contamination.

The reflection coefficient $\mathrm{R}$ can be calculated by the following formula: 


$$
\mathrm{R}=\frac{\mathrm{F}_{\mathrm{ref}}}{\mathrm{F}_{\mathrm{rad}}}
$$

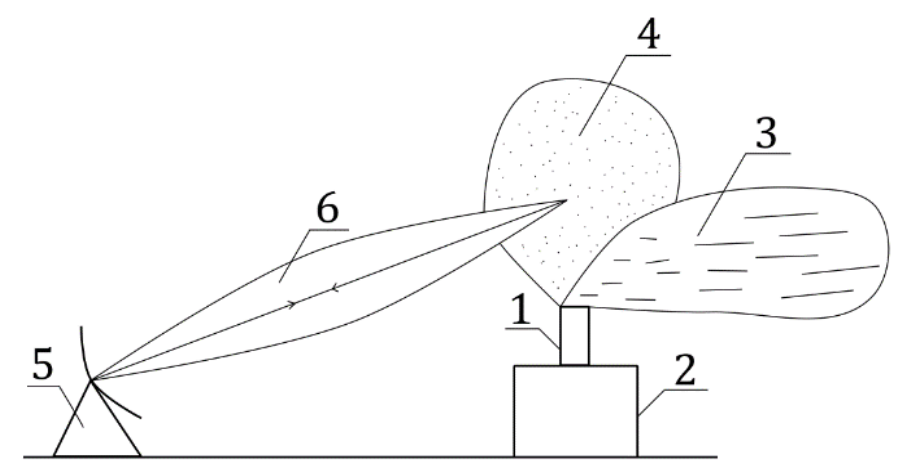

where $\mathrm{F}_{\text {ref }}$ - the amplitude of the reflected wave, $\mathrm{F}_{\text {rad }}$ - the amplitude of the emitted wave.

Fig. 3. Structural diagram of remote monitoring of the radiation state of the environment: 1 - nuclear power plant; 2 - ventilation stack; 3 - radiation emission flare; 4 - plasmoid; 5 - radar station; 6 - electromagnetic radiation (incident and reflected wave).

To estimate the value of $\mathrm{R}$ from the formed plasmoid, we will use the following assumption. Electromagnetic wave with wavelength $\lambda$ is incident on interface, one of which is air, the other is ionized layer of air. The formula can be applied to describe the reflection coefficient $\mathrm{R}$ as a jump of the derivative at the air interface and the ionized layer whereas the edge of the radial ion distribution has a sharp character:

$$
\mathrm{R}=\frac{\lambda_{0} \mathrm{e}^{2}}{4 \mathrm{M} \omega^{2}}\left(\frac{d N_{k}^{+}}{d r}\right)
$$

where $N_{k}^{+}$is the concentration of charged droplets.

If the exposure dose rate from the contaminating surface is recorded as uniformly distributed with the surface density $\mathrm{q}_{0}\left(\mathrm{~K}=\pi \mathrm{q}_{0} \mathrm{~K}_{\gamma}\right)$ and calculated for (3) the radial derivative, the following formula can be obtained:

$$
\mathrm{R}=\mathrm{K}^{1 / 4} \frac{\lambda_{0} e^{2}}{8 M \omega^{2}}\left(\frac{G}{k_{r}}\right)^{1 / 4}\left(2 \frac{k_{c}^{p} N_{k}^{g}+k_{c}^{n} N_{k}^{g}}{k_{r}}\right)^{1 / 2} \frac{1}{\varphi^{3 / 4}} \frac{d \varphi}{d r}
$$

where the values of $\frac{\mathrm{d} \varphi}{\mathrm{dr}}$ и $\varphi$ are calculated at the boundary of the radioactive contamination area.

It is possible to solve the system of equations obtained using (4) by measuring the reflection coefficient $\mathrm{R}$ at several wavelengths $\lambda_{0}$. We can calculate the value $\mathrm{K}$. It allows us to determine the value $\mathrm{q}_{0}$. This value contains information of air pollutants concentration.

\section{Results}

The dependence the reflection coefficient $\mathrm{R}$ on different wavelength values $\mathrm{R}$ was calculated for the test exposure dose in order to justify the use of the formula (4) for detecting radioactive contamination and determining the degree of its danger by the value of $q_{0}$. The calculation results were compared with the experiment. Figure 4 shows as an example the dependence the reflection coefficient $\mathrm{R}$ on the wavelength $\lambda$ for $\mathrm{P}_{\mathrm{rad}}=34 \mu \mathrm{R} / \mathrm{h}$. 


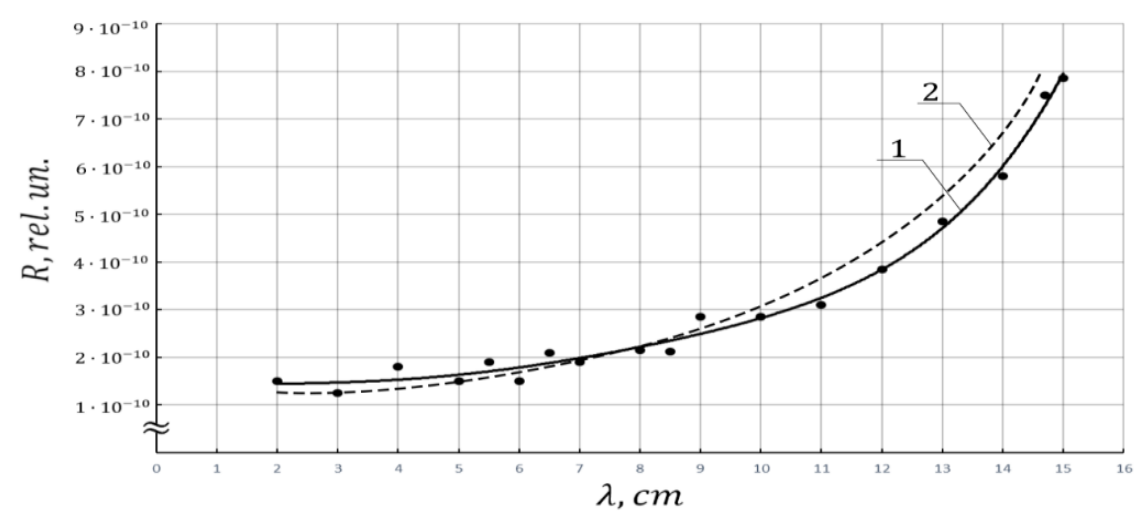

Fig. 4. The dependence the reflection coefficient $\mathrm{R}$ on the wavelength $\lambda$ of microwave radiation. The line 1 is an experimental dependence. The line 2 is the results of $R$ value calculation.

Analysis of the obtained dependencies shows that the nature of the change in the calculated and experimental dependence of the reflection coefficient $\mathrm{R}$ on the wavelength $\lambda$ of microwave radiation coincides. The difference between numerical results and experimental results is explained by the fact that (4) does not take into account the heterogeneity of the spatial distribution of positive ions. This value is quite difficult to predict, so an average value was taken. The difference of results is not more than $5 \%$, which allows to use (4) to determine the area of radioactive contamination and its degree of danger.

The change in $\mathrm{R}$ values from the power $\mathrm{P}_{\mathrm{rad}}$ of the exposure dose for different wavelength values $\lambda$ of the microwave radiation signal of the radar was investigated in order to confirm the validity of the use of the remote method of radiation monitoring of the atmosphere. Figure 5 shows one such dependence as an example.

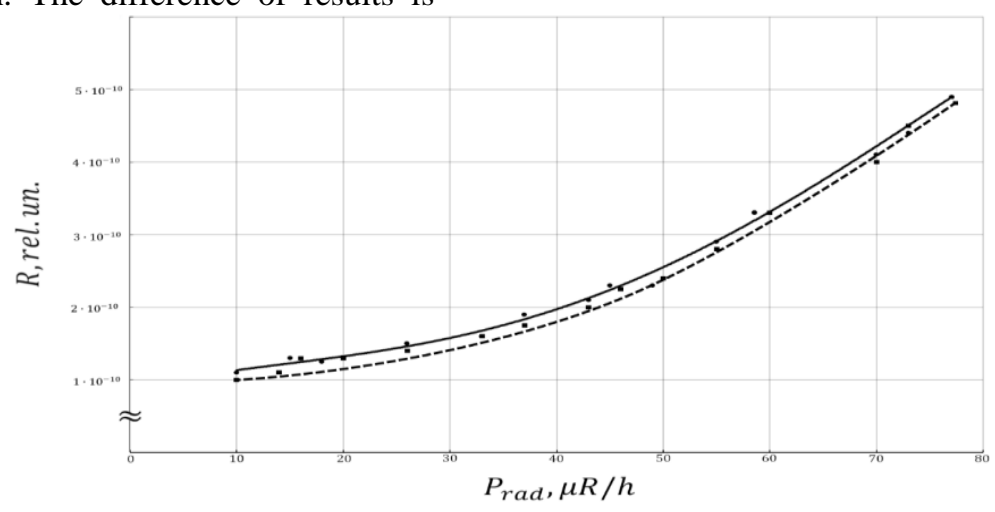

Fig. 5. The dependence the reflection coefficient $R$ on the power $P_{\text {rad }}$ of the exposure dose for different wavelengths of microwave radiation. Graphs 1 and 2 correspond to the value of $\lambda: 8 \mathrm{~cm}$ and $5 \mathrm{~cm}$.

The obtained results are the same as those obtained by various methods in other works [24, 34-40, 44-47]. This fact

confirms the feasibility of using the method proposed by us.

In addition, samples from experimental atmospheres were tested in 
a mobile laboratory. For this, the nuclear magnetic spectrometers is designed for express control were used [48-51]. The obtained research results also coincided with the data obtained by our developed radar method.

\section{Conclusion}

The results showed that the reflection coefficient $\mathrm{R} \sim \mathrm{P}_{\text {dis }}$ (emission power) at low $\mathrm{P}_{\mathrm{rad}}$ values. It allows to determine the cause of the release.

We have found that the reflection coefficient $\mathrm{R} \sim \mathrm{P}_{\mathrm{dis}}{ }^{\mathrm{z}}$ in general, where the value of $z$ varies from 0.22 to 0.55 taking into account the temperature and humidity conditions.

It is necessary to use radar with tunable $\lambda$ from 1 to $10 \mathrm{~cm}$, with a power of not less than $4 \mathrm{~kW}$ in a pulse in order to carry out a reliable study of the atmosphere, as well as the surface of the Earth, on which radioactive contamination may be present, near the NPP. In this case, plasmoid studies can be performed at distances greater than $300 \mathrm{~km}$. These distances are not available for other remote environmental monitoring methods. This allows you to effectively monitor the state of the atmosphere and predict the possibility of rainfall over long distances. This is especially important when carrying out various long-term works (for example, construction and others) [52-55].

\section{References}

1. T. Fejling, E. Torosyan, O. Tsukanova, O. Kalinina, IOP Conference Series: Materials Science and Engineering, 497(1) 012027 (2019)

2. V. Vilken, O. Kalinina, S. Barykin, E. Zolotova, IOP Conference Series: Materials Science and Engineering, 497(1) 012037 (2019)
3. O. Kalinina, E. Balchik, S. Barykin, MATEC Web of Conference, 23904021 (2018)

4. V. Vilken, O. Kalinina, A. Dubgorn, E35 Web of Conference, 3303012 (2018)

5. A. Bril, O. Kalinina, A. Levina, E35 Web of Conference, 3303004 (2018)

6. N.D. Agafonova, M.Y. Egorov, V.V. Sergeev, M.A. Gotovskii, P.A. Kruglikov, M.E. Lebedev, A.V. Sudakov, E.D. Fedorovich, B.S. Fokin, Atomic Energy, 123(3) 154158 (2018)

7. J. Kaikko, A. Mankonen, E. Vakkilainen, V. Sergeev, Energy Procedia, 120 572-579 (2017)

8. O.V. Novikova, A.N. Grishkin, I.S. Khrebetenko, N.A. Yudina, IOP Conference Series: Earth and Environmental Science, 288(1) 012065 (2019)

9. T. Bugaeva, A. Khabarov, O. Novikova, U. Plotkina, IOP Conference Series: Materials Science and Engineering, 497(1) 012056 (2019)

10. V.V. Davydov, V.I Dudkin, A.Yu. Karseev, Measurement Techniques, 58(3) 317-322 (2015)

11. V.V. Davydov, V.I. Dudkin, A.A. Petrov, N.S. Myazin, Technical Physics Letters, 42 692-698 (2016)

12. V.V. Davydov, Russian Physics Journal, 42(9) 822-825 (1999)

13. V.V. Davydov, V.I. Dudkin, A.Yu. Karseev, Russian Physics Journal, 58(2) 146-152 (2015)

14. M. Petrichenko, V. Sergeev, E. Kotov, D. Nemova, D. Tarasova, Advances in Intelligent Systems and Computing, 983 839-848 (2019) 
15. A.L. Sirotkina, E.D. Fedorovich, V.V. Sergeev, High Temperature, 56(5) 732-737 (2018)

16. T.J.B. Taweel, E. Sokolova, V. Sergeev, D. Solovev, IOP Conference Series: Materials Science and Engineering, 463(1) 032101 (2018)

17. D. Tarasova, A. Staritcyna, D. Nemova, K. Andreev, MATEC Web of Conferences, 5301007 (2016)

18. V.V. Davydov, V.I. Dudkin, A.Yu. Karseev, Optical Memory \& Neural Networks (Information Optics), 23(3) 170 - 176 (2014)

19. V.V. Davydov, V.I. Dudkin, A.U. Karseev, Optical Memory \& Neural Networks (Information Optics), 22(2) 112 - 117 (2013)

20. V.V. Davydov, V.I. Dudkin, A.Yu. Karseev, Optical Memory \& Neural Networks (Information Optics), 23(4) $259-264$ (2014)

21. V.V. Davydov, V.I. Dudkin, E.N. Velichko, A.Yu. Karseev, Journal of Optical Technology (A Translation of Opticheskii Zhurnal), 82(3) 132-135 (2015)

22. I.I. Kryshev, L.A. Kurydina, I.I. Linge, Atomic Energy, 117(3) 159163 (2014)

23. A.S. Podstrigaev, R.V. Davydov, V.Yu. Rud', V.V. Davydov, Lecture Notes in Computer Science (including subseries Lecture Notes in Artificial Intelligence and Lecture Notes in Bioinformatics), 11118 LNCS 624-630 (2018)

24. A.S. Podstrigaev, A.V. Smolyakov, V.V. Davydov, N.S. Myazin, M.G. Slobodyan, Lecture Notes in Computer Science (including subseries Lecture Notes in Artificial Intelligence and Lecture Notes in Bioinformatics), 11118 LNCS 509515 (2018)
25. R.V. Davydov, I.V. Saveliev, V.A. Lenets, M.Yu. Tarasenko, T.R. Yalunina, V.V. Davydov, V.Yu. Rud', Lecture Notes in Computer Science (including subseries Lecture Notes in Artificial Intelligence and Lecture Notes in Bioinformatics), 10531 LNCS 177-183 (2017)

26. A. P. Elokhin, Russian Meteorology and Hydrology, 35(5) 317-324 (2008)

27. V. B. Fadeenko, V. A. Kuts, D. A. Vasiliev, V. V. Davydov, Journal Physics: Conference Series, 1135(1) 012053 (2018)

28. A.V. Moroz, V.V. Davydov, V.Yu. Rud, Yu.V. Rud, V.C. Shpunt, A.P. Glinushkin, Journal of Physics: Conference Series, 1135(1) 012060 (2018)

29. V. B. Fadeenko, V. Yu. Rud, Yu.V. Rud, A.P Glinushkin, V.C. Shpunt, W. Hogland, Journal of Physics: Conference Series, 1038(1) 012030 (2018)

30. I.A. Zharikov, R.V. Davydov, V.A. Lyapishev, V.Yu. Rud, Yu.V. Rud, A.P. Glinushkin, Journal of Physics: Conference Series, 917(5) 052011 (2017)

31.R.V. Davydov, V.Yu. Rud, Yu.V. Rud, E.I. Terukov, Journal of Physics: Conference Series, 1124(8) 081039 (2018)

32. N.M. Grebenikova, K.J. Smirnov, V.V. Artemiev, V.V. Davydov, S.V. Kruzhalov, Journal of Physics: Conference Series, 1038(1) 012089 (2018)

33. R.V. Davydov, V.I. Antonov, A. V. Moroz, Proceedings of the 2018 IEEE International Conference on Electrical Engineering and Photonics, EExPolytech 2018, 8564378 236239 (2018) 
34. A. P. Elokhin, Technical Physics, 46(8) 1026-1036 (2001)

35. A. P. Elokhin, Atomic Energy, 112(4) 269-280 (2012)

36. A. P. Elokhin, Atomic Energy, 117(3) 206-215 (2015)

37. A. P. Elokhin, M. V. Zhilina, P. A. Parkhoma, Atomic Energy, 107(2) 140-143 (2009)

38. A. N. Didenko, Yu. P. Usov, Yu. G. Yushkov, I. V. Shamanin, O. V. Andreev, Atomic Energy, 80(1) 4752 (1996)

39. A. I. Ryabchikov, I. A. Ryabchikov, I. B. Stepanov, A. A. Sinebryukhov, Yu. P. Usov, Surface and Coatings Technology, 201(15) 6635-6637 (2007)

40. E. N. Kononov, S. A. Reshetnyak, L. A. Shelepin, V. A. Shcheglov, Technical Physics Letters, 22(9) 727728 (1996)

41. V.E. Fortov, A.A. Makarov, PhysicsUspekhi, 52(12) 1249-1265 (2009)

42. M.Yu. Tarasenko, V.V. Davydov, N.V. Sharova, V.A. Lenets, T.R. Yalunina, Lecture Notes in Computer Science (including subseries Lecture Notes in Artificial Intelligence and Lecture Notes in Bioinformatics), 10531 LNCS 227-232 (2017)

43. A.A. Petrov, V.V. Davydov, N.S. Myazin, Lecture Notes in Computer Science (including subseries Lecture Notes in Artificial Intelligence and Lecture Notes in Bioinformatics), 10531 LNCS 561-568 (2017)

44. A. P. Elokhin, and E. N. Kononov, Atomic Energy, 80(2) 135-142 (1996)

45. A. P. Elokhin, and E. N. Kononov, Atomnay Energiya, 80(2) 129-135 (1996)
46. K. A. Boyarchuk, and Yu. P. Svirko, Technical Physics Letters, 22(9) 575577 (1996)

47. K. A. Boyarchuk, Technical Physics, 44(3), 292-294 (1999)

48. V.V. Davydov, V.I. Dudkin, N.S. Myazin, Journal of Communications Technology and Electronics, 61(10) 1159-1165 (2016)

49. N.S. Myazin, S.E. Logunov, V.V. Davydov, V.Yu. Rud', N.M. Grebenikova, V.V. Yushkova, Journal of Physics: Conference Series, 929 (1) 012064 (2017)

50. V.V. Davydov, N.S. Myazin, Measurement Techniques, 60 491496 (2017)

51.E.V. Rykin, A.V. Moroz, K.J. Smirnov, V.V. Davydov, V.V. Yushkova, MATEC Web of Conference, 24512002 (2018)

52. V.V. Sergeev, M.R. Petrichenko, D.V. Nemova, E.V. Kotov, D.S. Tarasova, A.V. Nefedova, A.B. Borodinecs, Magazine of Civil Engineering, 84(8) 67-74 (2018)

53. V. Maslak, N. Nasonkina, V. Sakhnoskaya, S. Antonenko, D. Nemova, Procedia Engineering, 117(1) 985-994 (2015)

54. V. Mushchanov, V. Sievka, A. Veshnevska, D. Nemova, Procedia Engineering, 117(1) 10181026 (2015)

55. R. Davydov, V. Antonov, D. Molodtsov, A. Trebukhin, Advances in Intelligent Systems and Computing, 692 915-920 (2018) 